\title{
Simulation and experimental validation of single-phase series active power filter using PI and backstepping nonlinear controllers
}

\author{
Abdallah Ben Abdelkader, Othmane Abdelkhalek, Mohammed Amine Soumeur, Oussama Hafsi, \\ Abdeselem Chakar
}

Smart Grids \& Renewable Energies Laboratory, Faculty of Technology, University of Tahri Mohammed Bechar, Algeria

\section{Article Info \\ Article history: \\ Received Nov 21, 2019 \\ Revised Dec 27, 2019 \\ Accepted Feb 19, 2020 \\ Keywords: \\ Backstepping nonlinear Power quality issues Proportional integral PI Sag/swell, voltage harmonics Series active power filter Total harmonic distortion

\begin{abstract}
Nowadays, power distribution networks are focus mainly on power quality issues. Among the power disturbances, sag, swell and voltage harmonics are studied and deliberated in this research paper. These problems have negative impacts especially on the sensitive load, which have to be protected and secured against these problems. Therefore, to solve such disturbances, the series active power filter (SAPF) can be an efficient solution, which is used to compensate the voltage difference and to reduce the problem's effects on the power system. In this paper, the SAPF is simulated and experimentally validated, where two control methods are used to control the applied disturbances; which are classical proportional integral PI and nonlinear backstepping controllers. The control structure of the SAPF aims to reduce the error of the injection voltage closed loop, in addition to reduce the total harmonic distortion (THD) values below 5\% and within the specified ranges of the international IEEE-519 standard. From simulation results, the backstepping nonlinear controller has reacted more robustly and efficiently than the conventional PI controller.
\end{abstract}

This is an open access article under the CC BY-SA license.

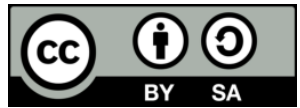

\section{Corresponding Author:}

Abdallah Ben Abdelkader,

Department of Electrical of Engineering,

Tahri Mohammed Bechar University,

BP 417 Route de Kenadsa, 08000 Bechar, Alegria.

Email: Abdallahbenabdelkader@yahoo.fr

\section{INTRODUCTION}

Given the demand of improving the power quality especially in industry, where the critical equipment and sensitive loads are widely used and their power supply should not interrupted. Here, uninterrupted, clean and regulated power supply is required when feeding loads that have important tasks. In other hand, most common voltage disturbances appear in alternative current appliances (AC) providing a reduction in voltage amplitude known as sag. Thus, sag and interruptions provide most of the industrial problems (90\%) that affect their supply quality [1]. Other, swell problem is also among disturbances that affect the power quality, which is defined by a rising in voltage amplitude above its nominal value [2]. In addition, harmonic distortion can provide huge problems in the whole of the power conversion chain such as heating the system components, mechanical oscillations, unpredictable behavior of protecting devices, and may cause damage [3,4].

Due to these problems, it is necessary to approve protecting devices and effective solution to solve such disturbances. In this paper, we focus on series active power filter (APFS) in order to mitigate sag-swell and harmonics [5-8] that affect our system. Thus, a serie compensator inserted between the source and 
the load called dynamic voltage restorer (DVR) is also implemented in this work to protect operating voltage of sensitive and critical appliances against sag problem especially [9-12]. APFS have the same topology as the active filter, with an excellent dynamic capability to restore the load voltage to i nominal value within a few milliseconds as well providing power disruption to the supplied loads. In other researches, the serie topology aims to compensate the sag with active power [13]. In power quality domain, various paper has used classical and intelligent controllers in order to improve the stability, robustness and excellent dynamic response of the APFS as mentioned in [4-18].The control strategies used in this paper such as PI, FLC, and SMC present robust and efficient results with different THD ratio, where SMC has provided the best ratio with $3 \%$. Models of the three controllers are developed mathematically as cited in various works such as [19-24], and adapted to our system topology.

This paper provides new method for applying adaptive backstepping controller in APFS and its operating principle. The control method based on nonlinear backstepping controller is used to compensate the voltage sages and swells in low and medium voltage distribution systems [25]. The rest of the paper in organized as follows: Section 1, present the APFS model with modeling of the power system, section 2 focus on the control strategies with a comparative study between the used strategies and finally, this paper ends with a conclusion.

\section{DESCRIPTION OF THE SYSTEM}

In this part, a brief description of the principal of the system element is mentioned.

\subsection{Series active power filter APFS}

In this paper, the studied system is composed mainly by three blocks, a programmable AC source to provide sag-swell and harmonics voltages scenarios, a sensitive load (medical equipment) and APFS. The APFS contains a single-phase PWM voltage source inverter in order to inject the compensating voltage by an injection transformer and an $\mathrm{Lf}, \mathrm{Cf}$ second order filer to eliminate high frequency caused by inverter switching actions. This inverter is supplied by a DC source as shown in Figure 1.

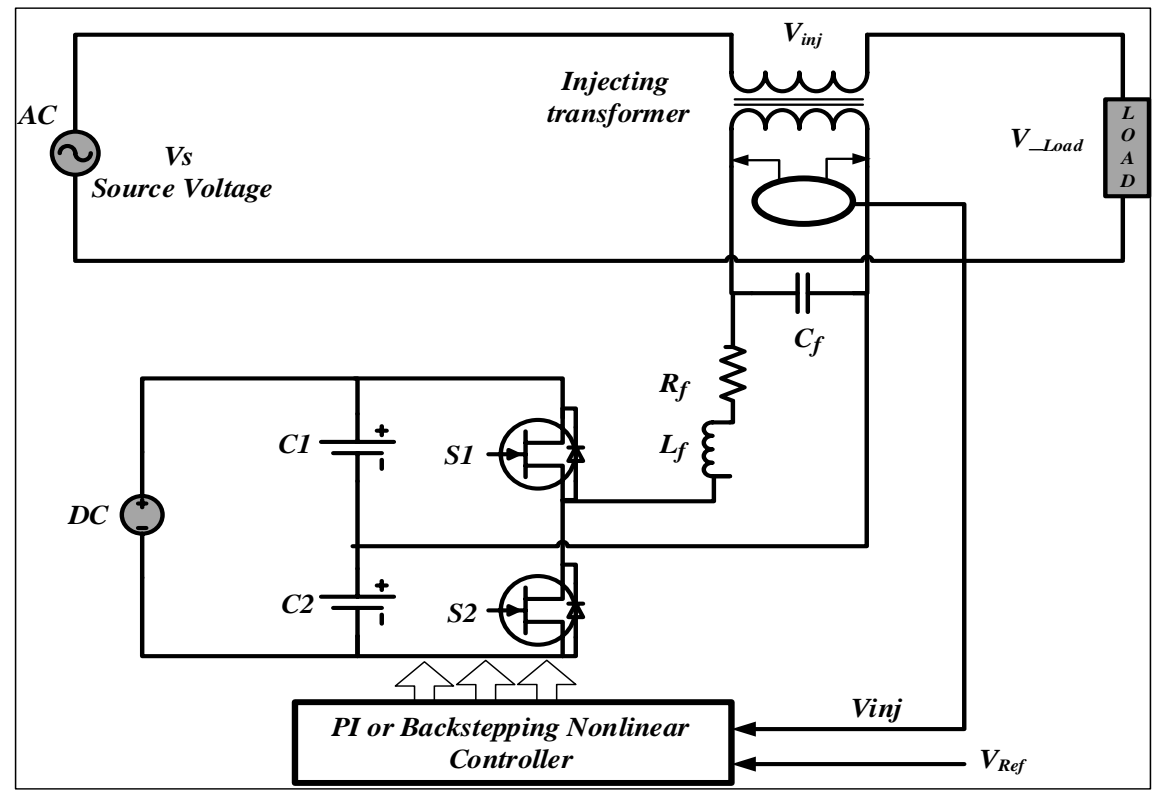

Figure 1. Single-phase series active power filter (APFS)

\subsection{Modeling of the APFS system}

This section deals with the mathematical modeling of the series active power filter APFS. The full structure of the APFS can be represented by a converter as shown in Figure 2, where Kirchhoff's voltage law (KLV) is applied to the AC closed circuit to get the following mathematical expression by [5]. The SAPF model shown in Figure 2 is modelled and represented by the following state space representation: Where $x_{1}$ and $x_{2}$ are the filter capacitor voltage $\mathrm{V}_{\mathrm{C}}$ and the filter inductor current iLf respectively. 


$$
\begin{aligned}
& m v_{0}=i_{L} R_{f}+L_{f} \frac{d i_{L}}{d t}+v_{i n j} \\
& v_{i n j}=i_{c} R_{c}+\frac{1}{C_{f}} \int\left(i_{c} d t\right)
\end{aligned}
$$

With:

$m$ : Control input to the series converter

$i_{L}: \quad$ Inductor current of the series converter

$v_{i n j}$ : Output voltage of the series converter

$v_{0}$ : DC link voltage

$L_{f}:$ Filtre inductance

$C_{f}:$ Filtre capacitance

$R_{f}$ : Equivalent series resistance (ESR) of inductor

$R_{c}$ : (ESR) of capacitor

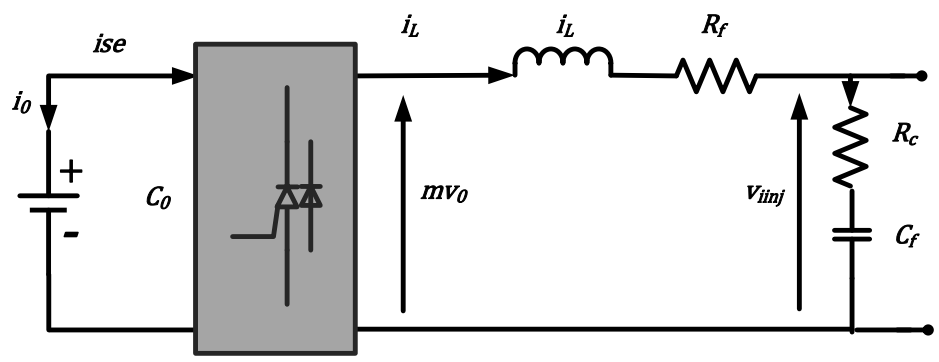

Figure 2. Equivalent circuit of series converter

$$
\begin{aligned}
& \widehat{m}(s) V_{0}=\hat{i}_{L}(s)\left(R_{f}+s L_{f}\right)+\hat{\widehat{V}}_{i n j}(s) \\
& \hat{V}_{i n j}(s)=\hat{i}_{c}(s)\left(R_{c}+\frac{1}{s C_{f}}\right) \\
& \dot{x}_{1}=\frac{1}{C} x_{2}-\frac{1}{C} i_{L} \\
& \dot{x}_{1}=\frac{1}{C} x_{2}-\frac{1}{C} i_{L}
\end{aligned}
$$

\section{CONTROL STRATEGIES OF THE SYSTEM}

The control strategies used in this work are PI and Backstepping Nonlinear controllers. Thus, a comparative study is made between the two methods in order to improve their performance and robustness in power quality. The two methods are described separately as follow:

\subsection{Proportional integrator PI controller}

The controller structure is based on a closed-control loop to regulate the injected voltage of the SAPF, where PWM signal is generated to the switching devices (IGBT) of the voltage source inverter VSI [7]. The PI controller can be defined by the mathematical expression of the transfer function in (7).

$$
H_{i}(s)=K_{p}+\frac{K_{i}}{s}
$$


The voltage error denoted eps is defined by the difference between the reference and the instantaneous values of the injection voltage. Therefore, PI controller determines instantaneous values of the error without considering their divergence and perturbations, which is defined by the derivate of the error $\Delta \mathrm{e}$ [7]. The transfer function of voltage-closed loop of the VSI is defined by (8):

$$
G_{v s e}(s)=\frac{\hat{v}_{i n j}(s)}{\hat{i}_{c}(s)}
$$

Figure 3 depicts the difference between the reference value of the injected voltage and its real-time operating value, which is the error signal and the input to the selected controller (PI). This voltage error is treated by the controller to generate the appropriate signal command to the switching devices (Mosfet) via the PWM generator. Thus, the obtained signal commands aim to provide the required injected voltage by the inverter to compensate for the error of the voltage.

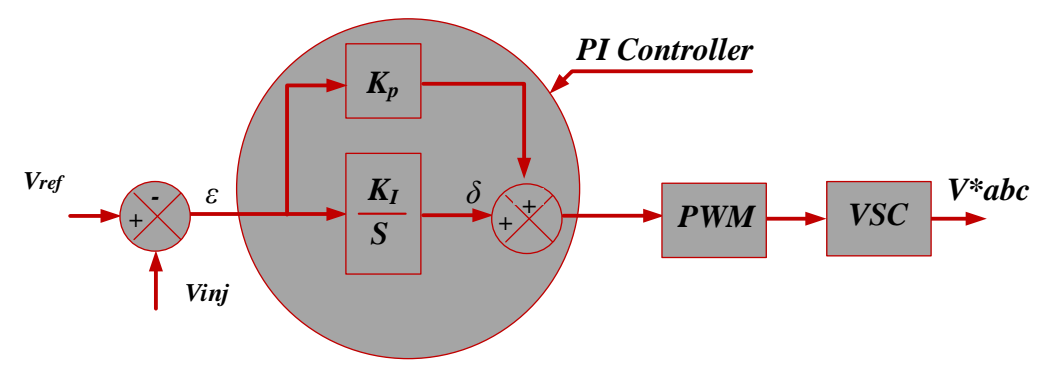

Figure 3. Controller PI with PWM and VSC

\subsection{Backstepping nonlinear control of APFS}

The backstepping control a nonlinear method based on lyapunov function, which can be considered as a passivation output with a storage function. Thus, this control method is a recursive design methodology that involves a systematic construction of feedback control laws and associated Lyapunov functions. The controller design can be reached in a number of steps that does not exceed the system order [25]. In this part the APFS system based on the proposed adaptive backstepping nonlinear controller and single-phase (levels) voltage source inverter. General block diagram of the system is shown in Figure 4.

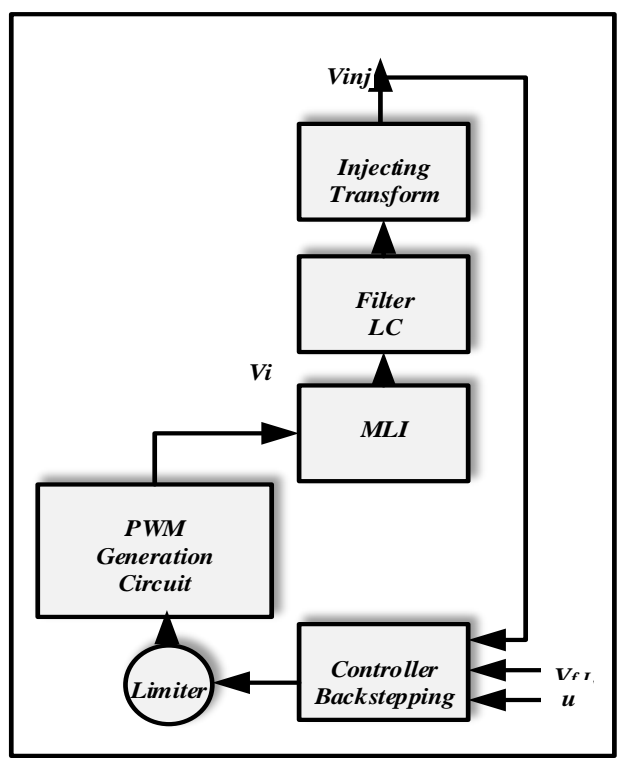

Figure 4. General block diagram of the adaptive nonlinear backstepping controller for APFS system 
The control objective is to enforce the system to inject a compensation voltage Vc represented by the state space variable $x_{1}$. This injected voltage is the difference voltage between the reference $\mathrm{Vr}$ and the instantaneous system voltage $\mathrm{Vs}$, this drop voltage can be defined by $\mathrm{u}$. In addition, the control problem caused by the nonminimum phase nature of the power converter is solved according to the indirect approach, where the direct output voltage regulation is unfeasible [25-28]. The controller design is given below in two main steps because of the order of the studied system $(3,4)$ :

Step 1: The output voltage error is defined by: $\dot{y}_{1}=\dot{x_{1}}-\dot{u}$. Then, deviating $y_{1}$ and substituting it from (5), we get:

$$
\dot{y}_{1}=\dot{x_{1}}-\dot{u}=\frac{1}{C} x_{2}-\frac{1}{C} i_{L}-\dot{u}
$$

where the term ${ }^{x_{2}} / C$ can be a virtual control input. From (5), we get the following:

$$
\begin{aligned}
& \dot{y_{1}}=-\alpha_{1} y_{1}\left(\alpha_{1}>0\right) \\
& \frac{x_{2}}{C}=-\alpha_{1} y_{1}+\frac{1}{C} i_{L}+\dot{u}
\end{aligned}
$$

where, alpha is a design parameter. While $x_{2} / C$ is not an effective input for the control design, the (9) is not valid for all value of the time $(t>=0)$. Hence, the desired value of the term $x_{2} / C$ can be defined by:

$$
\begin{aligned}
& \beta_{1}=\alpha_{1} y_{1}+\frac{1}{C} i_{L}+\dot{u} \\
& y_{2}=\frac{x_{2}}{C}-\beta_{1}
\end{aligned}
$$

where $\beta$ is the stabilization function. Then, if the error or $y_{1}=\left(x_{1}-u\right)$ is vanishing asymptotically, so the control objective is reached. Therefore, replacing $x_{2} / C$ is (5) by $\left(y_{2}+\beta_{1}\right)$, and then substituting from (10), we can get:

$$
\dot{y}_{1}=-\alpha_{1} y_{1}+y_{2}
$$

Step 2: In this step we derivate the error $y_{2}$, and substituting from (6) and (9), we get the following expression:

$$
\dot{y}_{2}=-\frac{1}{L C} x_{1}+\frac{1}{L C} v_{i}-\dot{\beta}_{1}
$$

From (7), we get:

$$
\dot{\beta_{1}}=\alpha_{1}^{2} y_{1}-\alpha_{1} y_{2}+\frac{1}{C} i_{L}+\ddot{u}
$$

Then, substituting from (10), we get:

$$
\dot{y}_{2}=-\frac{1}{L C} x_{1}+\frac{1}{L C} v_{1}-\alpha_{1}^{2} y_{1}+\alpha_{1} y_{2}+\frac{1}{C} i_{L}-\ddot{u}
$$

By choosing the following function $V=\left(y_{1}^{2}+y_{2}^{2}\right)$, we can derivate the state $\left(y_{1}, y_{2}\right)$ to zero, where the time variation of the function $\mathrm{V}$ along the $\left(y_{1}, y_{2}\right)$ trajectory is expressed as follow:

$$
\dot{V}=y_{1} \dot{y_{1}}+y_{2} \dot{y_{2}}
$$




$$
\dot{V}=-\alpha_{1} y_{1}^{2}-\alpha_{2} y_{2}^{2}+y_{2}\left[y_{1}+\alpha_{2} y_{2}+\dot{y}_{2}\right]
$$

where $\alpha_{2}$ is a design parameter and $\dot{y}_{2}$ is to be substituted from (15). From (16), the equilibrium $\left(y_{1}, y_{2}\right)=(0,0)$ is globally asymptomatically stable if the third term $\left(-\alpha_{1} y_{1}^{2}\right)$ is set to zero. Therefore, we can get the following control law[25].

$$
v_{i}=x_{1}+L C\left(\alpha_{2}^{2}-1\right) y_{1}-L C\left(\alpha_{1}+\alpha_{2}\right) y_{2}+L i_{L}+L C \ddot{u}
$$

where the output from the controller is the inverter voltage is function in modulation index.

\section{RESULTS AND DISCUSSION}

In this section, we discuss the analytical and experimental results of the different control methods used in this study. First, we present simulation data, after we discuss its results. Thus, we present experimental results with a detailed discussion.

\subsection{Simulation results}

Simulation test has made in MATLAB Simulink® in order to improve the performance of the used control strategies such as PI and Backstepping Nonlinear. The simulation circuit is shown in Figure 5. Thus, simulation data are summarized in the following Table 1. The simulation results of the APFS are presented in order to improve its capability of ameliorating the power quality. The results are discussed separately, where a comparative analyses is made between the two controllers in the cas harmonics. Figures 6 and 7 present the voltage waveforms of PIand the Backstepping nonlinear. The THD of the source voltage was $48.34 \%$. As shown, the APFS has compensated the voltage harmonics successfully. The two controllers have presented various excellent results, which is shown through ameliorating the voltage form and reducing the THD value. The THD has become $4.15 \%$ with PI controller, $1.98 \%$ with the Backstepping nonlinear. The following Figures 8 and 9 show the spectral analysis for the three controllers. As a result, the sliding mode controller has presented the lowest THD value, which reflects the robustness and the efficiency of the control structure.

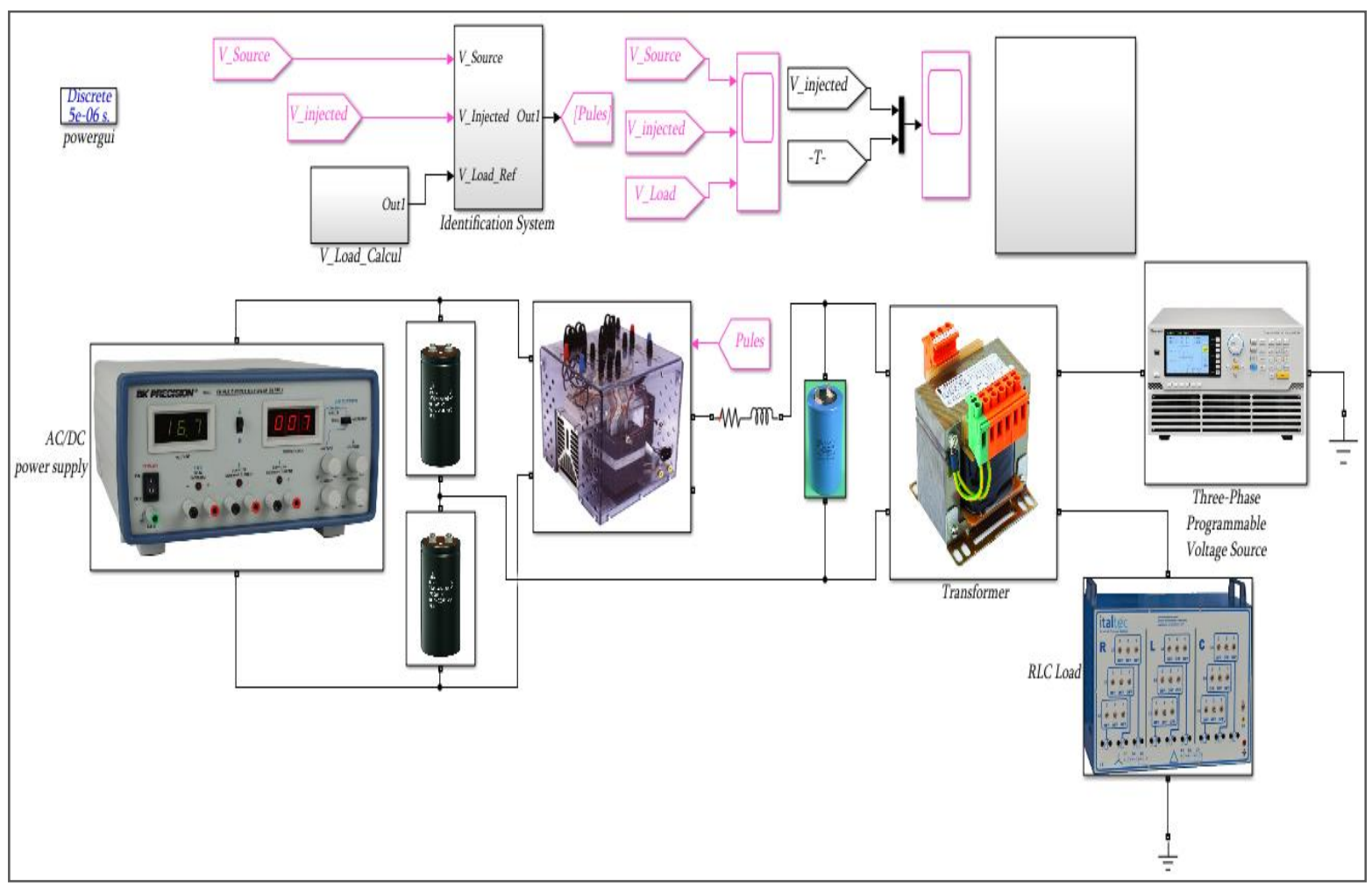

Figure 5. Simulation diagram of the system 


\begin{tabular}{cc}
\multicolumn{2}{c}{ Table 1. Electrical parameters } \\
\hline Parameters & Values \\
\hline Source voltage frequency f & $50 \mathrm{~Hz}$ \\
Source voltage Vs & $5.7 \mathrm{Vrms}$ \\
Load resistance RL & $12.3 \Omega$ \\
Cf (LC filter inductance) & $1 \mathrm{nF}$ \\
Lf(LC filter capacitance) & $9 \mathrm{mH}$ \\
Transformer & $12 \mathrm{~V} / 230 \mathrm{~V} / 1 \mathrm{KVA}$ \\
DC-bus capacitor, DC-bus & $2200 \mathrm{uF}-$ \\
reference voltage & $\mathrm{Vdc} *=35 \mathrm{~V}$ \\
Kp, Ki Simulation results & $\mathrm{Kp}=7.2-\mathrm{Ki}=33$ \\
$\mathrm{Kp}$, Ki Experimental results & $\mathrm{Kp}=8.8-\mathrm{Ki}=4,24$ \\
\hline
\end{tabular}
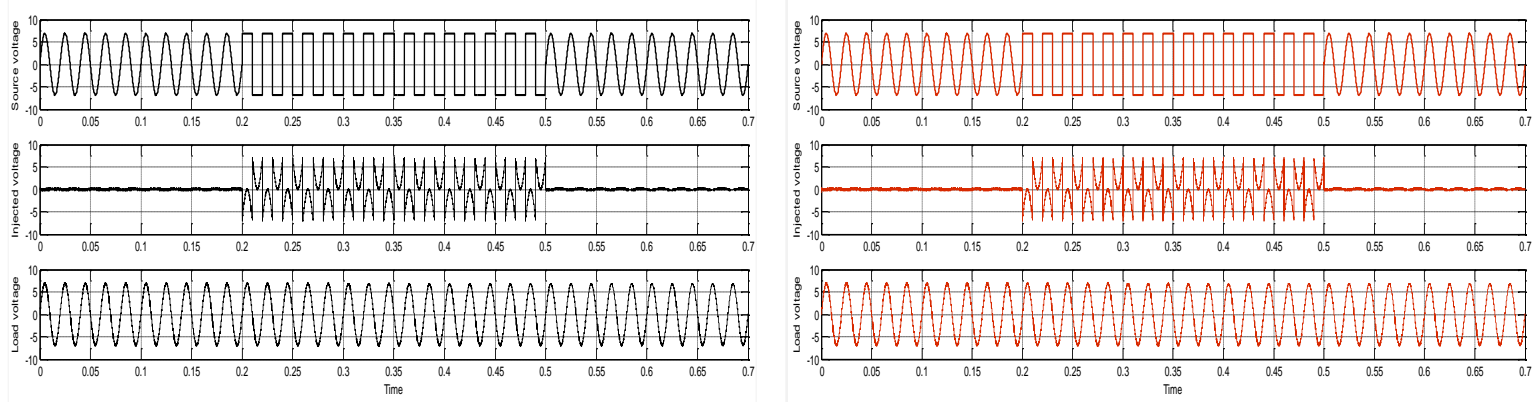

Figure 6. Simulation voltage waveforms for PI controller

Figure 7. Simulation voltage waveforms for backstepping nonlinear controller

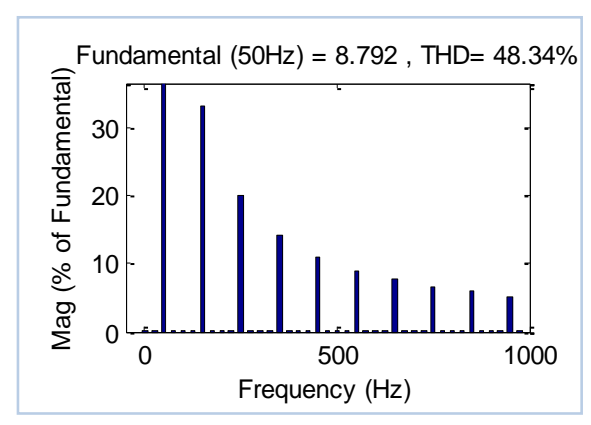

(a)

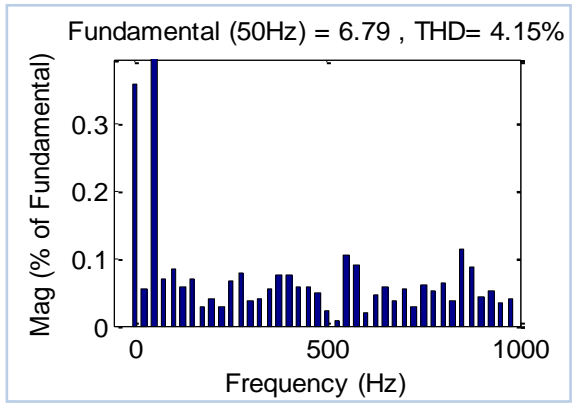

(b)

Figure 8. Spectral analysis for PI controller of the (a) source voltage, (b) load voltage

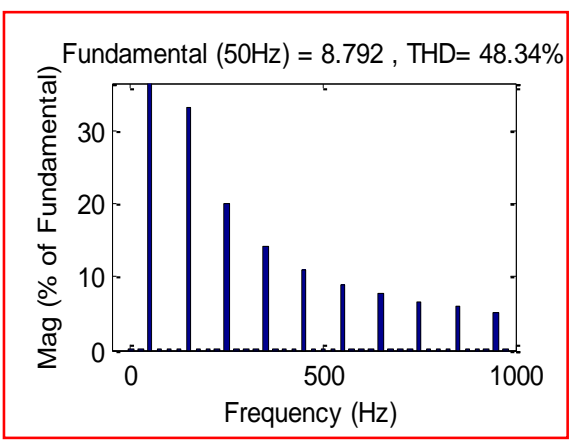

(a)

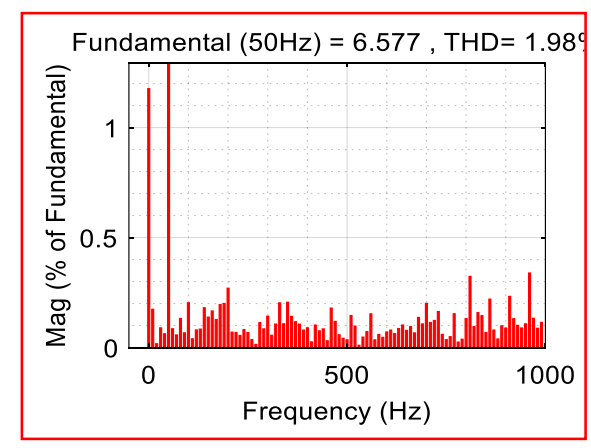

(b)

Figure 9. Spectral analysis for backstepping nonlinear controller of the (a) source voltage, (b) load voltage 


\subsection{Experimental results}

The experimental results to validate the simulation tests and improve the robustness of the used control methods. The experimental test has realized and elaborated in Smart Grid and Renewable Energies Laboratory (SGRE-Lab) in the University of TAHRI Mohamed-Béchar-Algeria. The experimental prototype includes a dSPACE card 1104 platform Texas Instrument with a TMS32F240 DSP connected with a PC (pentium) in order to enable automatic implementation of the control methods directly from Matlab Simulink as illustrated in Figure 10. Thus, the test bench consists of a voltage inverter, an inductor, an injection transformer, Hall current/voltage sensors, linear load and a programmed source. The PWM switching gates was selected $15 \mathrm{KHz}$, which are generated from the Dspace card in real time experimental tests. Thus, a linear load was selected. As seen, the APFS has the ability to mitigate voltage harmonics provided by the grid and supplied to the connected load. The voltage harmonics are provided by the voltage inverter, which was connected in parallel with the source voltage. Figure 11 depictes the waveforms of the source, the load and the injected voltages during the experimental test taking into consideration normal operating mode (befor and afeter applying the selected issue), and during the application of the selected issue (sag).

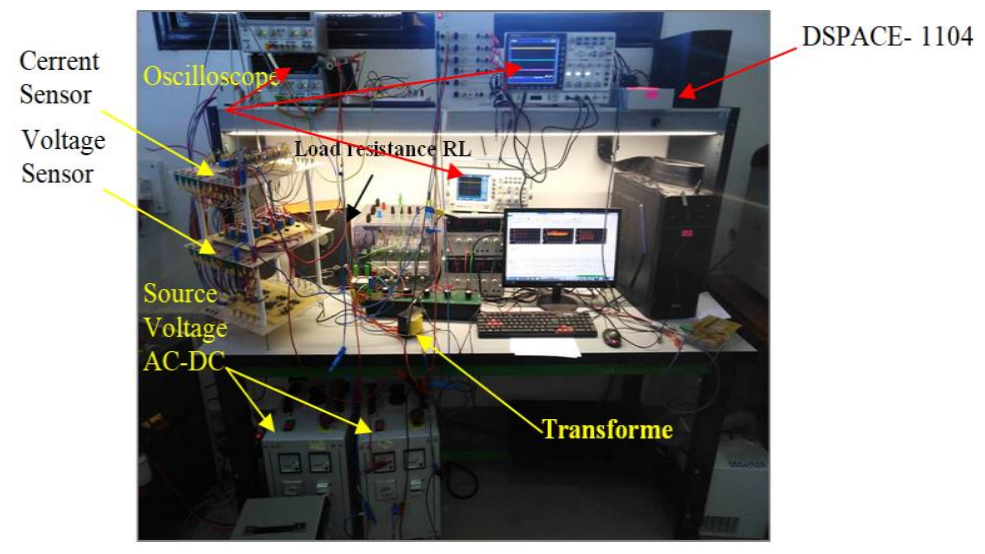

Figure 10. The photograph of the shunt APFS prototype

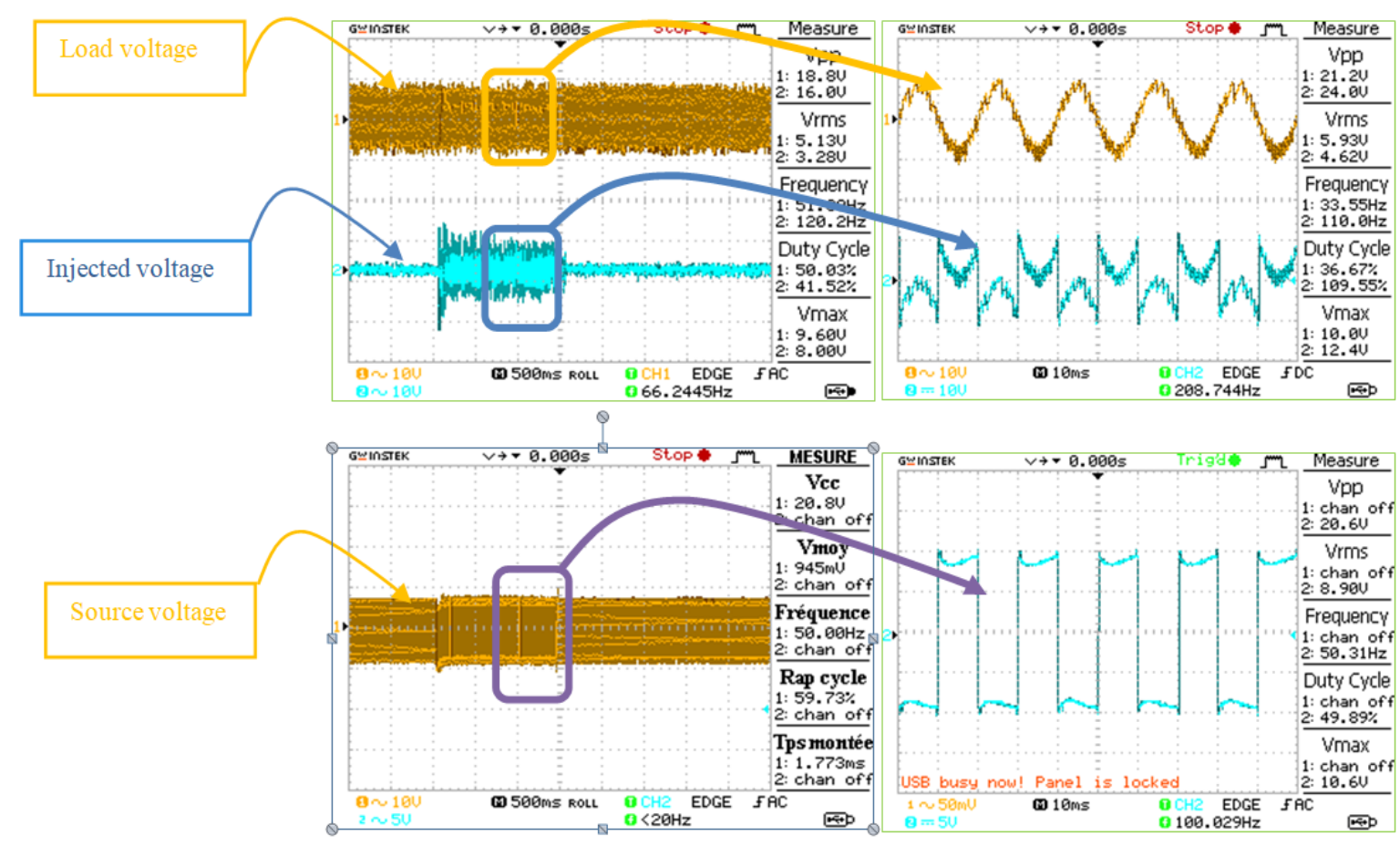

Figure 11. Experimental voltage waveforms for PI Controller 
As montioned in Figure 12, the spectral analysis of the source voltage was about $46.4 \%$ and the load voltage was $4.8 \%$ using the PI controller. Then, Figure 13 support these results with the experimental obtained curves of the injected voltage while traking its reference value during the applied sag phenomina during [5.6 s-6.3 s]. In the previous paper [4, 29], fuzzy logic FLC and sliding mode SMC controllers have presented satsifactor results compared with the classical PI, where the THD values after the correction were about 4\%-3.8\% respectively. Figure 14 presents the waveforms of the voltages using the SMC method. In this paper, using backstepping nonlinear controller, the obtained results are unique and better than the previously applied methods. Exactly, the THD was about 3\% during the application of the same issue and during the same period as seen in Figure 15. Therfore, the injected voltage was more efficient following the reference value as seen in Figure 16.

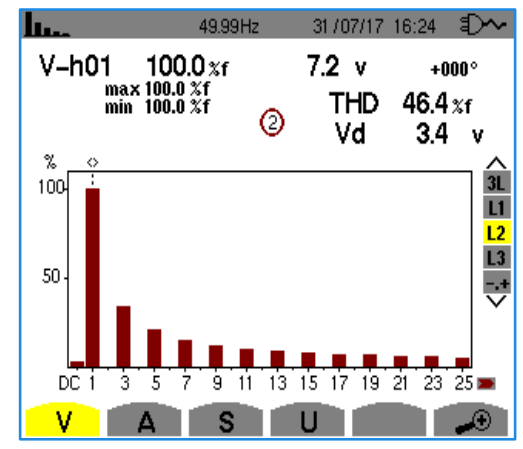

(a)

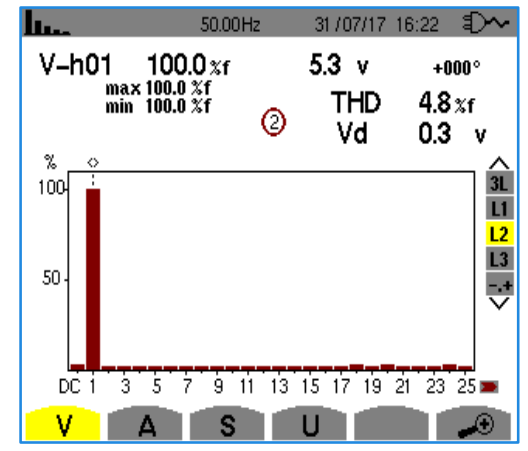

(b)

Figure 12. Spectral analysis of the (a) source voltage, (b) load voltage for Pi controller

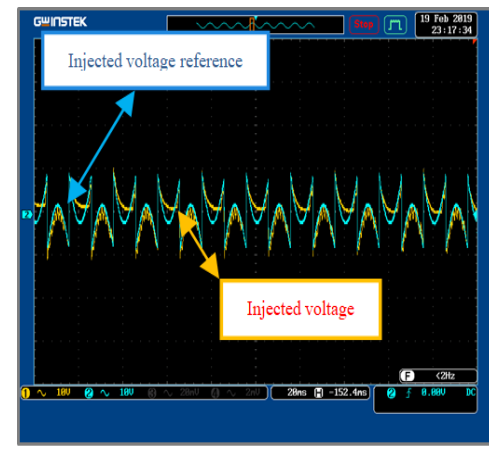

Figure 13. Experimental voltage waveforms for PI controller
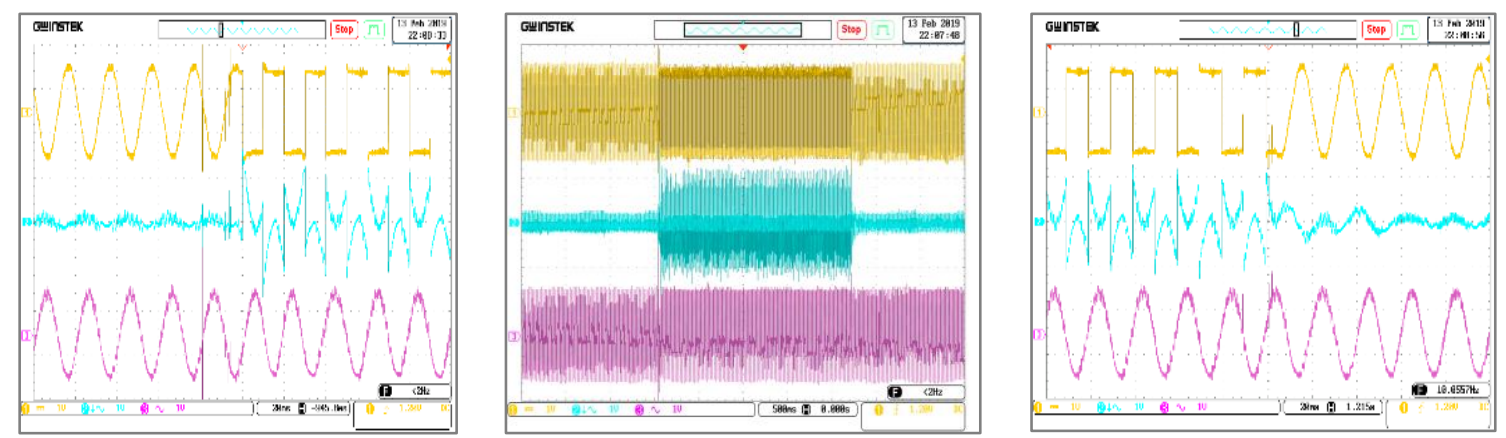

Figure 14. Experimental voltage waveforms for backstepping nonlinear controller
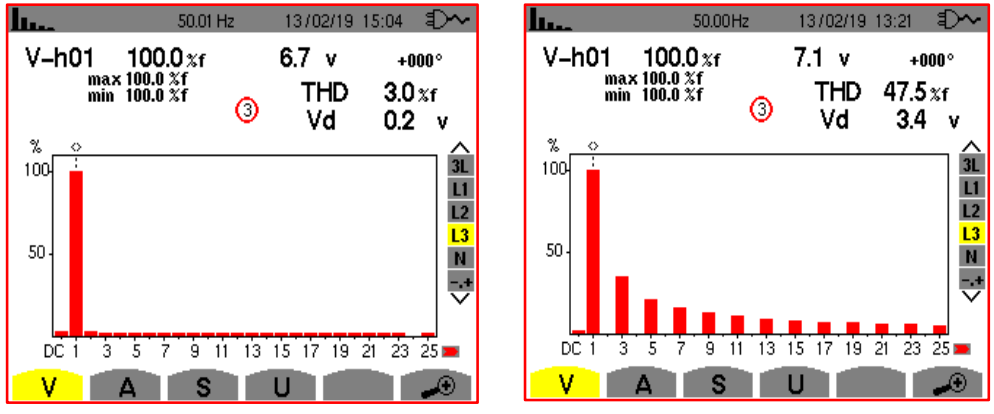

Figure 15. Spectral analysis of the (a) source voltage, (b) load voltage for backstepping nonlinear controller.

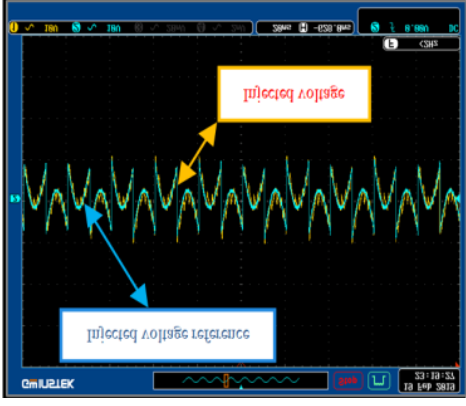

Figure 16. Experimental voltage waveforms for backstepping nonlinear controller 
It seems clearly that the application of the backstepping non-linear control methd has ameliorated the performance of the SAPF when eliminating the voltage harmonics caused by the programmable source. As seen in Figures 15 and 16, the injected voltage by the SAPF via the injection transformer has followed its reference value efficiently with the backstepping compared by the conventional PI controller. As a comparison between the two controllers, the injected voltage using the backstepping controller is characterized by its fast response time during transient period, with a negligible debasement compared with the PI. Hence, the backstepping has proven less volte error compared with the PI due to its tuned gains represented by alpha $\alpha$ and beta $\beta$.

\section{CONCLUSION}

Through this brief study, we have presented a topic about improving the quality of energy using the series active power filter APFS. The APFS has presented fast and specific reactions with thevoltage perturbance phenomenon such as harmonics. As previously explained, the used control method were and Backstepping nonlinear, which have been chosen to show the reaction of APFS with perturbations using classicaland nonlinear control methods. In this study, we focused only on two parameters, which are the waveform of source and load voltages and the THD ratio. Thus, the controllers have presented excellent results in both simulation and experimental tests, with respecting to the norms of the IEEE 519 standard. Exactly, the three methods has compensating the harmonics voltages by the filer, whit keeping a sinusoidal waveform of the load voltage despite the perturbance. In addition, among these controllers, the backstepping nonlinear has improved the lowest THD value compared with PI controller due to the robustness of its control structure. This work can be considered as a continuation of the previous research paper, where we have presented more improvement of the power quality with the Backstepping nonlinear.

\section{ACKNOWLEDGEMENTS}

At the end of this work, I thank all doctor colleges and professors who participated in this work with their information's and who helped me as possible. I don't forget to thank Professor Abdelkhalek Othmane, Smart Grid and Renewables Energies Laboratory (SGRE-Lab) for providing all necessary equipment and material and moral assistance.

\section{REFERENCES}

[1] A. Prasai and D. M. Divan, "Zero-energy sag correctors-Optimizing dynamic voltage restorers for industrial applications," IEEE Transactions on Industry Applications, vol. 44, no. 6, pp. 1777-1784, 2008.

[2] H. Akagi, E. H. Watanabe, and M. Aredes, "Instantaneous power theory and applications to power conditioning," John Wiley \& Sons, 2017.

[3] E. C. dos Santos, C. B. Jacobina, J. A. A. Dias, and N. Rocha, "Single-phase to three-phase universal active power filter," IEEE Transactions on Power Delivery, vol. 26, no. 3, pp. 1361-1371, 2011.

[4] A. Ben Abdelkader, O. Abdelkhalek, and A. Allali, "Experimental validation of single phase series active power filter using fuzzy control technique," International Journal of Power Electronics and Drive Systems, vol. 9, no. 2, pp. 591-601, 2018.

[5] A. Meena, S. Islam, S. Anand, Y. Sonawane, and S. Tungare, "Design and control of single-phase dynamic voltage restorer," Indian Academy of Sciences.Sadhana, vol. 42, no. 8, pp. 1363-1375, 2017.

[6] R. Lawrence, "Power quality and electrical reliability: Where does the responsibility lie? Energy Engineering," vol. 106, no. 6, pp. 23-33, 2009.

[7] H. Akagi and K. Isozaki, "A hybrid active filter for a three-phase 12-pulse diode rectifier used as the front end of a medium-voltage motor drive," IEEE transactions on power Electronics, vol. 27, no. 1, pp. 69-77, 2012.

[8] A. Chaoui, J. P. Gaubert, F. Krim, and G. Champenois, "PI controlled three-phase shunt active power filter for power quality improvement," Electric Power Components and Systems, vol. 35, no. 12, pp. 1331-1344, 2007.

[9] M. H. Bollen and M. H. Bollen, "Understanding power quality problems: voltage sags and interruptions," IEEE press New York, 2000.

[10] A. Sannino, M. G. Miller, and M. H. Bollen, "Overview of voltage sag mitigation," IEEE Power Engineering Society Winter Meeting, pp. 2872-2878, 2000.

[11] D. J. Carnovale and T. J. Hronek, "Power quality solutions and energy savings-what is real? Energy Engineering," vol. 106, no. 3, pp. 26-50, 2009.

[12] N. Athanasiadis, "Power quality solutions for voltage sags using dynamic voltage restorers," Electric Power Components and Systems, vol. 31, no. 2, pp. 159-170, 2003.

[13] J. G. Nielsen, M. Newman, H. Nielsen, and F. Blaabjerg. Control and testing of a dynamic voltage restorer (DVR) at medium voltage level," IEEE Transactions on Power Electronics, vol. 19, no. 3, pp. 806-813, 2004.

[14] P. S. Babu and N. Kamaraj, "Performance investigation of dynamic voltage restorer using PI and fuzzy controller," IEEE 2013 International Conference on Power, Energy and Control (ICPEC), pp. 467-472, 2013. 
[15] F. B. Ajaei, S. Afsharnia, A. Kahrobaeian, and S. Farhangi, "A fast and effective control scheme for the dynamic voltage restorer," IEEE transactions on power delivery, vol. 26, no. 4, pp. 2398-2406, 2011.

[16] F. Jowder, "Design and analysis of dynamic voltage restorer for deep voltage sag and harmonic compensation," IET Generation, Transmission \& Distribution, vol. 3, no. 6, pp. 547-560, 2009.

[17] M. J. Newman, D. G. Holmes, J. G. Nielsen, and F. Blaabjerg, "A dynamic voltage restorer (DVR) with selective harmonic compensation at medium voltage level," 38th IAS Annual Meeting. Conference Record of the Industry Applications Conference, pp. 1228-1235, 2003.

[18] A. Pandey, R. Agrawal, R. S. Mandloi, and B. Sarkar, "Sliding mode control of dynamic voltage restorer by using a new adaptive reaching law," Journal of The Institution of Engineers (India): Series B, vol. 98, no. 6, pp. 579-589, 2017.

[19] F. Mekri, M. Machmoum, B. Mazari, and N. A. Ahmed, "Determination of voltage references for series active power filter based on a robust PLL system," IEEE International Symposium on Industrial Electronics, ISIE 2007, pp. 473-478, 2007.

[20] K. Sandhya, A. J. Laxmi, and M. Soni, "Design of PI and fuzzy controllers for dynamic voltage restorer (DVR)," AASRI Procedia, vol. 2, pp. 149-155, 2012.

[21] Y. Chang, L. Jinjun, W. Xiaoyu, and W. Zhaoan, "A novel control of series active power filter without harmonics detection," IEEE Power Electronics Specialists Conference, PESC 2007, pp. 1112-1115, 2007.

[22] A. Ramos, I. Nuez, and V. Feliu, "Linearisation method and control for series active power filter by means of pulse-width modulation," IEE Proceedings-Electric Power Applications, vol. 153, no. 3, pp. 337-342, 2006.

[23] F. B. Ajaei, S. Farhangi, and R. Iravani, "Fault current interruption by the dynamic voltage restorer," IEEE Transactions on Power Delivery, vol. 28, no. 2, pp. 903-910, 2013.

[24] D. M. Vilathgamuwa, A. R. Perera, and S. S. Choi, "Voltage sag compensation with energy optimized dynamic voltage restorer," IEEE Transactions on Power Delivery, vol. 18, no. 3, pp. 928-936, 2003.

[25] N. H. Saad, "Backstepping nonlinear control strategy for dynamic voltage restorer using multilevel inverter," The 16th International Middle East Power Systems Conference (MEPCON'14), January 2014

[26] K. M. I. Kanellakopoulos and P. V. Kokotovic, "Nonlinear and adaptive control design," John Willy \& Sons, New York, 1995.

[27] El Fadil H., H. Ouadi, F. Giri, and M. Haloua, "Nonlinear control of power converters," Internal report, LAP, ISRMA, 2002.

[28] K. R. Raju, A. Nayeemuddin, and B. Rajani, "Robust control of SAG/SWELL mitigation using multi converter unified power quality conditioner," Int. Journal of Modern Engineering Research, vol. 2, no. 3, pp. 937-940, 2012.

[29] A. B. Abdelkader, O. Abdelkhalek, I. K. Bousserhane, M. A. Hartani, and A. Omari, "A comparative study and experimental validation on single phase series active power filter control strategies using PI, FLC and sliding mode controllers," Int.l Journal of Power Electronics and Drive Systems, vol. 10, no. 2, pp. 731-743, 2019. 